\title{
Syntheses and properties of star- and dumbbell-shaped POSS derivatives containing isobutyl groups
}

\author{
Hitoshi Araki and Kensuke Naka
}

Dumbbell-shaped isobutyl-substituted C2-linked polyhedral oligomeric silsesquioxane (POSS) ((1,2-bis(heptaisobutyl-T8silsesquioxy)ethane) IBDE), C3-linked POSS ((1,3-bis(heptaisobutyl-T8-silsesquioxy)propane) IBDP) and C6-linked POSS ((1,6bis(heptaisobutyl-T8-silsesquioxy)hexane) IBDH) were prepared by corner capping of heptaisobutyltricycloheptasiloxane trisilanol (IB7-OH) with 1,2-bis(trichlorosilyl)ethane, 1,3-bis(trichlorosilyl)propane and 1,6-bis(trichlorosilyl)hexane, respectively. The star-shaped POSS derivative ((octakis[3-(heptaisobutyl-T8-silsesquioxy) propyldimethylsiloxy]-Q8-silsesquioxane) 9POSIB) was prepared by hydrosilylation of heptaisobutylallyl-T8-silsesquioxane (IB7A1) and octadimethylsiloxy-Q8-silsesquioxane using Karstedt's catalyst. The star and dumbbell structures of the obtained compounds were confirmed by ${ }^{1} \mathrm{H}-,{ }^{13} \mathrm{C}$ - and ${ }^{29} \mathrm{Si}$-nuclear magnetic resonance and matrix-assisted laser desorption ionization time-of-flight mass spectrometry analyses. With spin coating and subsequent baking at $120^{\circ} \mathrm{C}$, the star-shaped POSS compound formed an optical transparent film, but all of the dumbbellshaped POSS compounds formed opaque whitish films. The refractive index of the transparent film was 1.4567, which was higher than that of a corresponding random silsesquioxane. 9POSIB showed significantly higher thermal stability than did the dumbbell-shaped POSS compounds. Thermogravimetric analysis of the star-shaped POSS derivative showed a clear baseline shift at $24^{\circ} \mathrm{C}$, indicative of the glass-transition temperature. However, IBDE, IBDP and IBDH showed no clear baseline shift. The melting points of IBDE, IBDP, IBDH and 9POSIB were observed at 231, 231, 239 and $96^{\circ} \mathrm{C}$, respectively. The lower melting point and appearance of the glass-transition point in 9POSIB suggested its lower crystallinity, which promotes the formation of a transparent film.

Polymer Journal (2012) 44, 340-346; doi:10.1038/pj.2011.133; published online 21 December 2011

Keywords: dumbbell shaped; film formability; POSS; star shaped

\section{INTRODUCTION}

Silsesquioxanes, hybrid polymer materials consisting of organic substituents and inorganic backbones, have attracted widespread interest because of their excellent thermal, mechanical, optical and electrical properties. ${ }^{1}$ The most common process for the preparation of silsesquioxane materials is a sol-gel method using the corresponding silicone monomers. ${ }^{2,3}$ However, for complete condensation into a film, this process requires thermal curing at high temperatures exceeding $200^{\circ} \mathrm{C}$. Such high curing temperatures are not suitable for application of film coatings onto common organic materials. To develop lower-temperature processable materials based on silsesquioxanes, structurally well-defined ladder-type silsesquioxanes and polyhedral oligomeric silsesquioxanes (POSSs) have been considered as attractive candidates. ${ }^{4-7}$

Polyhedral oligomeric silsesquioxane compounds with well-defined cube-like structures, denoted $\left(\mathrm{RSiO}_{3 / 2}\right)_{8}$, have been extensively researched as the nanoscale building blocks of organic-inorganic hybrid materials. ${ }^{3}$ One way of using POSS compounds is the direct cross-linking of POSS units with small organic molecules to form three-dimensional networks. ${ }^{8,9}$ However, optically transparent films of a single POSS compound are rarely formed without cross-linking reagents because of their high symmetry and crystallinity. Recently, we reported that dumbbell-shaped POSS derivatives linked by simple aliphatic chains can be used, depending on their aliphatic chains, to form optically transparent films. ${ }^{10}$ Those dumbbell-shaped POSS compounds are the first examples of optical transparent POSS films exhibiting thermoplastic properties. As crystallinity and thermal characteristics of POSS molecules are very much dependent on their organic substituents, further studies are required to develop various thermoplastic POSS derivatives with the desired properties. Here, we synthesized different isobutyl-substituted POSS derivatives and studied their properties. We found that the formation of an optically transparent film using isobutyl-substituted POSS derivatives depended on their shapes. By spin coating and subsequent baking at $120^{\circ} \mathrm{C}$, we found that a star-shaped POSS derivative formed an optical transparent film, whereas dumbbell-shaped isobutyl-substituted POSS compounds formed opaque whitish films. There are a few reports about star-shaped POSS derivatives in the literature. Mitsudo

Department of Chemistry and Materials Technology, Graduate School of Science and Technology, Kyoto Institute of Technology, Goshokaido-cho, Matsugasaki, Sakyo-ku, Kyoto, Japan

Correspondence: Professor K Naka, Department of Chemistry and Materials Technology, Graduate School of Science and Technology, Kyoto Institute of Technology, Goshokaidocho, Sakyo-ku, Kyoto 606-8585, Japan.

E-mail: naka@chem.kit.ac.jp

Received 20 August 2011; revised 5 October 2011; accepted 28 October 2011; published online 21 December 2011 
and co-workers ${ }^{11}$ synthesized dendritic POSS derivatives for application to homogeneous catalyst supports. Wang et al. ${ }^{12}$ synthesized a star-shaped POSS supramolecule. However, no bulk properties of these compounds were studied.

\section{EXPERIMENTAL PROCEDURE}

\section{Materials}

All of the solvents and chemicals used here were obtained as reagent-grade quality and used without further purification. All of the reactions were performed under a nitrogen atmosphere.

\begin{abstract}
Measurements
${ }^{1} \mathrm{H}-(400 \mathrm{MHz}),{ }^{13} \mathrm{C}-(100 \mathrm{MHz})$ and ${ }^{29} \mathrm{Si}-(80 \mathrm{MHz})$ nuclear magnetic resonance (NMR) spectra were obtained using a Bruker PDX-300 instrument (Bruker Biospin, Rheinstetten, Germany). Matrix-assisted laser desorption ionization time-of-flight mass spectrometry (MALDI-TOF-MS) data were obtained using a Bruker Autoflex II instrument (Bruker Daltonics, Billerica, MA, USA). Fourier transform infrared (FTIR) spectra were obtained using a Jasco FT/ IR-4100 spectrometer (Jasco, Tokyo, Japan) and embedding samples in $\mathrm{KBr}$ pellets. Ultraviolet-vis spectra were obtained using a Jasco spectrophotometer V-670 KKN (Jasco). Differential scanning calorimetry data were obtained using a TA Instruments 2920-Modulated differential scanning calorimetry instrument (TA Instruments, New Castle, DE, USA). Thermogravimetric analysis was performed using a TA Instruments Hi-Res-Modulated thermogravimetric analysis 2950 thermogravimetric analyzer (TA Instruments). Refractive indices were measured using a Metricon Model 2010 prism coupler (Metricon, Pennington, NJ, USA). Gel-permeation chromatography (GPC) was performed using a Tosoh LC-8220 GPC instrument (Tosoh, Tokyo, Japan) with a TSKgel SuperHM-H column using tetrahydrofuran (THF) as an eluent.
\end{abstract}

General synthesis procedure of dumbbell-shaped POSS derivatives containing isobutyl groups

Heptaisobutyltricycloheptasiloxane trisilanol (IB7-OH) $(2.5 \mathrm{~g}, 3.16 \mathrm{mmol})$, dry THF $(75 \mathrm{ml})$ and triethylamine $(4.42 \mathrm{ml}, 3.52 \mathrm{mmol})$ were charged into a round-bottomed flask at room temperature under an $\mathrm{N}_{2}$ atmosphere. $\alpha, \omega-$ Bis(trichlorosilyl)alkane $(1.52 \mathrm{mmol})$ dissolved in THF $(5 \mathrm{ml})$ was added dropwise to the solution at $0{ }^{\circ} \mathrm{C}$, and $\mathrm{Et}_{3} \mathrm{~N}-\mathrm{HCl}$ salt appeared as a white solid. The reaction mixture was magnetically stirred at $0{ }^{\circ} \mathrm{C}$ for $1 \mathrm{~h}$ and then stirred at room temperature for $3 \mathrm{~h}$. The precipitates were removed by filtration, and the filtrate was concentrated under reduced pressure. The resultant solid was dissolved in $100 \mathrm{ml}$ of hexane and washed with distilled water and brine. The solution was dried by placing it over $\mathrm{MgSO}_{4}$, and then it was filtered and concentrated. The resultant solid was purified by recrystallization with an ethyl acetate $/ \mathrm{MeOH}=5 / 5$ solution.

\section{1,2-Bis(heptaisobutyl-T8-silsesquioxy)ethane}

Yield: $21 \% .{ }^{1} \mathrm{H}$ NMR $\left(\mathrm{CDCl}_{3}, 400 \mathrm{MHz}\right): \delta 1.86\left(m, 14 \mathrm{H}, \mathrm{Si}-\mathrm{CH}_{2}-\mathrm{CH}-\right.$ $\left.\left(\mathrm{CH}_{3}\right)_{2}\right), 0.96\left(d, J=6.6 \mathrm{~Hz}, 84 \mathrm{H}, \quad \mathrm{Si}-\mathrm{CH}_{2}-\mathrm{CH}-\left(\mathrm{CH}_{3}\right)_{2}\right), 0.60 \quad(m, 4 \mathrm{H}$, $\left.\mathrm{Si}-\mathrm{CH}_{2}-\mathrm{CH}_{2}-\mathrm{Si}, 28 \mathrm{H}, \mathrm{Si}-\mathrm{CH}_{2}-\mathrm{CH}-\left(\mathrm{CH}_{3}\right)_{2}\right) .{ }^{13} \mathrm{C} \mathrm{NMR}\left(\mathrm{CDCl}_{3}, 100 \mathrm{MHz}\right): \delta$ $25.70,25.67,23.90,23.87,22.52,22.46,3.49 .{ }^{29} \mathrm{Si} \mathrm{NMR}\left(\mathrm{CDCl}_{3}, 80 \mathrm{MHz}\right): \delta$ $-7.08,-67.59,-67.91$. FTIR (KBr): $v=2954,2928,2907,2870,1465,1402$, $1383,1366,1332,1230,1109,1038,954,837,742,569,480,433 \mathrm{~cm}^{-1}$. MALDITOF-MS $\left(\mathrm{m} / \mathrm{z},[\mathrm{M}+\mathrm{H}]^{+}\right): 1659.533$ (calc.); 1659.800 (observed).

\section{1,3-Bis(heptaisobutyl-T8-silsesquioxy)propane}

Yield: $14 \% .{ }^{1} \mathrm{H}$ NMR $\left(\mathrm{CDCl}_{3}, 400 \mathrm{MHz}\right): \delta 1.85\left(m, 14 \mathrm{H}, \mathrm{Si}-\mathrm{CH}_{2}-\mathrm{CH}-\right.$ $\left.\left(\mathrm{CH}_{3}\right)_{2}\right), 1.52\left(\mathrm{br}, 2 \mathrm{H}, \mathrm{Si}-\mathrm{CH}_{2}-\mathrm{CH}_{2}-\mathrm{CH}_{2}-\mathrm{Si}\right) 0.96(d, J=6.6 \mathrm{~Hz}, 84 \mathrm{H}$, $\left.\mathrm{Si}-\mathrm{CH}_{2}-\mathrm{CH}-\left(\mathrm{CH}_{3}\right)_{2}\right), 0.67\left(t, J=8.0 \mathrm{~Hz}, 4 \mathrm{H}, \mathrm{Si}-\mathrm{CH}_{2}-\mathrm{CH}_{2}-\mathrm{CH}_{2}-\mathrm{Si}\right), 0.60(d$, $\left.J=6.8 \mathrm{~Hz}, 28 \mathrm{H}, \mathrm{Si}-\mathrm{CH}_{2}-\mathrm{CH}-\left(\mathrm{CH}_{3}\right)_{2}\right) .{ }^{13} \mathrm{C} \mathrm{NMR}\left(\mathrm{CDCl}_{3}, 100 \mathrm{MHz}\right): \delta 25.71$, $23.89,23.86,22.54,22.50,16.20,15.86 .{ }^{29} \mathrm{Si} \mathrm{NMR}\left(\mathrm{CDCl}_{3}, 80 \mathrm{MHz}\right): \delta-67.78$, $-67.86,-67.92$. FTIR (KBr): $v=2954,2929,2907,2871,1464,1401,1383$, $1366,1332,1230,1111,1038,954,837,742,567,477,434 \mathrm{~cm}^{-1}$. MALDI-TOFMS $\left(m / z,[\mathrm{M}+\mathrm{H}]^{+}\right): 1673.549$ (calc.); 1673.717 (observed).

\section{1,6-Bis(heptaisobutyl-T8-silsesquioxy)hexane}

Yield: $30 \% .{ }^{1} \mathrm{H}$ NMR $\left(\mathrm{CDCl}_{3}, 400 \mathrm{MHz}\right): \delta 1.85\left(\mathrm{~m}, 14 \mathrm{H}, \mathrm{Si}_{-} \mathrm{CH}_{2}-\mathrm{CH}-\right.$ $\left.\left(\mathrm{CH}_{3}\right)_{2}\right), 1.38$ (br, $4 \mathrm{H}, \mathrm{Si}-\mathrm{CH}_{2}-\mathrm{CH}_{2}-\mathrm{CH}_{2}-\mathrm{CH}_{2}-\mathrm{CH}_{2}-\mathrm{CH}_{2}-\mathrm{Si}$ ), 1.29 (br, $4 \mathrm{H}$, $\left.\mathrm{Si}-\mathrm{CH}_{2}-\mathrm{CH}_{2}-\mathrm{CH}_{2}-\mathrm{CH}_{2}-\mathrm{CH}_{2}-\mathrm{CH}_{2}-\mathrm{Si}\right), 0.95\left(d, J=6.6 \mathrm{~Hz}, 84 \mathrm{H}, \mathrm{Si}-\mathrm{CH}_{2}-\mathrm{CH}-\right.$ $\left.\left(\mathrm{CH}_{3}\right)_{2}\right), 0.60\left(m, 4 \mathrm{H}, \mathrm{Si}-\mathrm{CH}_{2}-\mathrm{CH}_{2}-\mathrm{CH}_{2}-\mathrm{CH}_{2}-\mathrm{CH}_{2}-\mathrm{CH}_{2}-\mathrm{Si}, 28 \mathrm{H}, \mathrm{Si}-\mathrm{CH}_{2}-\right.$ $\left.\mathrm{CH}-\left(\mathrm{CH}_{3}\right)_{2}\right) .{ }^{13} \mathrm{C}$ NMR $\left(\mathrm{CDCl}_{3}, 100 \mathrm{MHz}\right): \delta 32.64,25.70,25.68,23.89,23.87$, 22.71, 22.54, 22.51, 12.15. ${ }^{29} \mathrm{Si} \mathrm{NMR}\left(\mathrm{CDCl}_{3}, 80 \mathrm{MHz}\right): \delta-67.07,-67.77$, -67.92 . FTIR (KBr): $v=2954,2928,2869,1460,1230,1108,1041,954,742$, $667,508,487,417 \mathrm{~cm}^{-1}$. MALDI-TOF-MS $\left(\mathrm{m} / \mathrm{z},[\mathrm{M}+\mathrm{H}]^{+}\right)$: 1715.596 (calc.); 1715.669 (observed).

Octakis[3-(heptaisobutyl-T8-silsesquioxy) propyldimethylsiloxy]Q8-silsesquioxane

Heptaisobutylallyl-T8-silsesquioxane (IB7A1) $(0.477 \mathrm{~g}, 0.557 \mathrm{mmol})$, octadimethylsiloxy-Q8-silsesquioxane $(0.070 \mathrm{~g}, 0.069 \mathrm{mmol})$ and dry THF $(0.7 \mathrm{ml})$ were charged into a Schlenk flask at room temperature under an $\mathrm{N}_{2}$ atmosphere. Karstedt's catalyst, dissolved in xylene $(0.1 \mathrm{M}, 55 \mu \mathrm{l})$, was added to the solution. The reaction mixture was magnetically stirred at $40^{\circ} \mathrm{C}$ for $24 \mathrm{~h}$ and concentrated under reduced pressure. Silica gel column chromatography $($ Hexane/EtOAc $=9 / 1)$ was used to remove unreacted raw materials and catalyst from the resultant residue to obtain the crude product. The crude product, including oligomeric byproducts, was purified by fractionation with GPC using $\mathrm{CHCl}_{3}$ as the eluent to produce a white solid. Yield: $14 \%$.

${ }^{1} \mathrm{H}$ NMR $\left(\mathrm{CDCl}_{3}, 400 \mathrm{MHz}\right): \delta 1.85\left(m, 56 \mathrm{H}, \mathrm{Si}-\mathrm{CH}_{2}-\mathrm{CH}-\left(\mathrm{CH}_{3}\right)_{2}\right), 1.45$ (br, $\left.16 \mathrm{H}, \mathrm{Si}-\mathrm{CH}_{2}-\mathrm{CH}_{2}-\mathrm{CH}_{2}-\mathrm{Si}\right), 0.95\left(d, J=6.6 \mathrm{~Hz}, 336 \mathrm{H}, \mathrm{Si}-\mathrm{CH}_{2}-\mathrm{CH}-\right.$ $\left.\left(\mathrm{CH}_{3}\right)_{2}\right), 0.67\left(\mathrm{br}, 32 \mathrm{H}, \mathrm{Si}-\mathrm{CH}_{2}-\mathrm{CH}_{2}-\mathrm{CH}_{2}-\mathrm{Si}\right), 0.60\left(\mathrm{~m}, 112 \mathrm{H}, \mathrm{Si}-\mathrm{CH}_{2}-\mathrm{CH}-\right.$ $\left.\left(\mathrm{CH}_{3}\right)_{2}\right), 0.12\left(s, 48 \mathrm{H}, \mathrm{Si}\left(\mathrm{CH}_{3}\right)_{2}\right) .{ }^{13} \mathrm{C} \mathrm{NMR}\left(\mathrm{CDCl}_{3}, 100 \mathrm{MHz}\right): \delta 25.68,23.87$, $23.85,22.51,22.49,21.32,16.44,16.23,-0.46 .{ }^{29} \mathrm{Si} \mathrm{NMR}\left(\mathrm{CDCl}_{3}, 80 \mathrm{MHz}\right): \delta$ $12.08,-67.75,-67.89,-108.94$. FTIR (KBr): $v=2955,2927,2908,2871,1464$, 1401, 1366, 1333, 1230, 1110, 953, 908, 837, 742, 684, 669, 615, 556, 507, 485, $474,438 \mathrm{~cm}^{-1}$. MALDI-TOF-MS $\left(\mathrm{m} / \mathrm{z},[\mathrm{M}+\mathrm{Na}]^{+}\right): 7901.348$ (calc.); 7901.205 (observed).

\section{Ran-9POSIB-pre}

A solution of aqueous $1 \mathrm{~N} \mathrm{HCl}(0.32 \mathrm{~g})$ and distilled water $(1.44 \mathrm{~g})$ were added dropwise to a methanol $(2.7 \mathrm{ml})$ and THF $(23.9 \mathrm{ml})$ solution containing isobutyltrimethoxysilane $(4.040 \mathrm{~g}, \quad 22.4 \mathrm{mmol})$, propyltrimethoxysilane $(0.532 \mathrm{~g}, 3.2 \mathrm{mmol})$, tetraethoxysilane $(0.674 \mathrm{~g}, 3.2 \mathrm{mmol})$ and dimethyldimethoxysilane $(0.389 \mathrm{~g}, 3.2 \mathrm{mmol})$ at room temperature into a reflux condenser setup. The mixture was refluxed for $3 \mathrm{~h}$ with magnetic stirring. The reactant was concentrated in a rotary evaporator and dried under reduced pressure at $50{ }^{\circ} \mathrm{C}$ for $2 \mathrm{~h}$ to yield a viscous liquid. ${ }^{1} \mathrm{H}$ NMR $\left(\mathrm{CDCl}_{3}, 400 \mathrm{MHz}\right): \delta$ a $1.86(\mathrm{br}, 7 \mathrm{H}$, $\left.\mathrm{Si}-\mathrm{CH}_{2}-\mathrm{CH}-\left(\mathrm{CH}_{3}\right)_{2}\right), 1.43$ (br, $\left.2 \mathrm{H}, \mathrm{Si}-\mathrm{CH}_{2}-\mathrm{CH}_{2}-\mathrm{CH}_{3}\right), 0.96$ (br, $3 \mathrm{H}, \mathrm{Si}-\mathrm{CH}_{2}-$ $\left.\mathrm{CH}_{2}-\mathrm{CH}_{3}, 56 \mathrm{H}, \mathrm{Si}-\mathrm{CH}_{2}-\mathrm{CH}-\left(\mathrm{CH}_{3}\right)_{2}\right), 0.63$ (br, $2 \mathrm{H}, \mathrm{Si}-\mathrm{CH}_{2}-\mathrm{CH}_{2}-\mathrm{CH}_{3}, 14 \mathrm{H}$, $\left.\mathrm{Si}-\mathrm{CH}_{2}-\mathrm{CH}-\left(\mathrm{CH}_{3}\right)_{2}\right) 0.14$ (br, $\left.6 \mathrm{H}, \mathrm{Si}-\left(\mathrm{CH}_{3}\right)_{2}\right) .{ }^{13} \mathrm{C} \mathrm{NMR}\left(\mathrm{CDCl}_{3}, 100 \mathrm{MHz}\right)$ : $\delta 25.75,23.84,22.83,17.51,16.33,14.85,0.47$. FTIR (KBr): $v=2957,2930$, 2910, 2896, 2874, 1468,1400,1384,1368, 1335, 1263, 1231, 1134-1029, 907, $893,837,802,740$.

\section{Preparation of coating solutions and coated films}

The coating solutions of the dumbbell- and star-shaped POSS derivatives were prepared as follows. 1,2-Bis(heptaisobutyl-T8-silsesquioxy)ethane (IBDE), 1,3bis(heptaisobutyl-T8-silsesquioxy)propane (IBDP), 1,6-bis(heptaisobutyl-T8silsesquioxy)hexane (IBDH) and octakis[3-(heptaisobutyl-T8-silsesquioxy) propyldimethylsiloxy]-Q8-silsesquioxane (9POSIB) (0.064 g) were dissolved in hexane $(0.368 \mathrm{~g})$ and octane $(0.368 \mathrm{~g})$. All coating solutions were filtered through a $0.45-\mu \mathrm{m}$ pore size polypropylene membrane before use. The coating solutions of the dumbbell- and star-shaped POSS derivatives were spin coated onto soda-lime glass pieces and baked at $120^{\circ} \mathrm{C}$ for $3 \mathrm{~min}$ on a hot plate.

The random silsesquioxanes precursor (Ran-9POSIB-Pre) was dissolved in 2-propanol and filtered through a membrane filter to prepare the coating solutions. The coating solutions were spin coated onto either soda-lime glass pieces or silicon wafers, pre-baked at $120^{\circ} \mathrm{C}$ for $3 \mathrm{~min}$ on a hot plate and cured at $200^{\circ} \mathrm{C}$ for $15 \mathrm{~min}$ under ambient atmosphere. The cured films were lifted off the glass with a spatula for FTIR analysis. Ran-9POSIB: FTIR (KBr): $v=2957$, 
2930, 2910, 2874, 1468,1400,1384, 1368, 1335, 1263, 1231, 1116-1037, 907, $893,837,808,802,740$.

\section{RESULTS AND DISCUSSION}

Syntheses and characterization of dumbbell- and star-shaped POSS derivatives

Dumbbell-shaped C2-linked POSS (IBDE), C3-linked POSS (IBDP) and C6-linked POSS (IBDH) were prepared by corner capping of IB7$\mathrm{OH}$ with 1,2-bis(trichlorosilyl)ethane, 1,3-bis(trichlorosilyl)propane and 1,6-bis(trichlorosilyl)hexane, respectively (Scheme 1). All of the products were purified by recrystallization using an ethyl acetate/ $\mathrm{MeOH}=5 / 5$ solution. The star-shaped POSS derivative was prepared by hydrosilylation of heptaisobutylallyl-T8-silsesquioxane (IB7A1) and octadimethylsiloxy-Q8-silsesquioxane using Karstedt's catalyst (Scheme 2). The product was purified using silica gel column chromatography to remove both unreacted raw materials and the catalyst to obtain a crude product that includes the oligomeric byproducts. The crude product was purified by fractionation with GPC using $\mathrm{CHCl}_{3}$ as an eluent. The purities of all the purified compounds were confirmed by GPC analysis, in which impurity peaks are barely noticeable, as shown Figure 1. The low yields of the purified POSS derivatives were due to the formation of relatively large amounts of oligomeric byproducts.

Dumbbell structures of IBDE, IBDP and IBDH were confirmed by ${ }^{1} \mathrm{H}-,{ }^{13} \mathrm{C}-$ and ${ }^{29} \mathrm{Si}-\mathrm{NMR}$ and MALDI-TOF-MS analyses. Figure 2 shows the ${ }^{1} \mathrm{H}-\mathrm{NMR}$ spectra of IBDE, IBDP and IBDH. The peaks in the spectra derived from the isobutyl groups of IBDE were observed at 1.85, 0.96 and 0.60 p.p.m. The peak assigned to the ethylene linker, which was confirmed by the integral ratio of the peaks at 1.85 and 0.60 p.p.m., overlapped with that of the isobutyl group at 0.60 p.p.m., The ${ }^{1} \mathrm{H}-\mathrm{NMR}$ spectra of IBDP and IBDH also showed peaks corresponding to the isobutyl groups and to the propylene and hexylene linkers, respectively. The broader peaks of the linker units compared with those of the isobutyl groups indicate that the mobility of linker units was suppressed by POSS moieties. The integral ratios of the linker parts and isobutyl groups in IBDP and IBDH are consistent with theoretical values. The ${ }^{13} \mathrm{C}-\mathrm{NMR}$ spectrum of IBDE showed only one sharp peak for the linker carbons at 3.48 p.p.m. and three split peaks derived from the isobutyl carbons in IBDE, indicating two different environments for the isobutyl groups (Figure 3). The peak patterns of the linker carbons in the ${ }^{13} \mathrm{C}-\mathrm{NMR}$ spectra of IBDP and IBDH also confirmed the existence of dumbbell structures (Supplementary Figures S1 and 2). Ideally, four different Si environments are observed as four peaks in the ${ }^{29} \mathrm{Si}$-NMR spectra of POSS derivatives prepared by corner capping of partially condensed silsesquioxanes. The number of observed peaks is sometimes reduced to two or three because of overlapping peaks. The ${ }^{29}$ Si-NMR spectra of IBDE, IBDP and IBDH showed three peaks (Supplementary Figures S4-6). These observations provide additional evidence for the existence of dumbbell structures. The MALDI-TOF-MS results provide conclusive evidence of the formation of dumbbell structures for all the compounds.

The star structure of 9POSIB was confirmed by ${ }^{1} \mathrm{H}-,{ }^{13} \mathrm{C}$ - and ${ }^{29} \mathrm{Si}-$ NMR and MALDI-TOF-MS analyses. Figure 4 shows the ${ }^{1} \mathrm{H}-\mathrm{NMR}$ spectrum of 9POSIB. Peaks in the NMR spectrum assigned to the propylene and methyl groups of the linkers were observed at 1.45, 0.67 and 0.12 p.p.m. The integral ratio of the propylene, methyl and isobutyl groups in the ${ }^{1} \mathrm{H}-\mathrm{NMR}$ spectrum agreed with the theoretical value. The ${ }^{13} \mathrm{C}-\mathrm{NMR}$ spectrum of $9 \mathrm{POSIB}$ showed four peaks assigned to the linker part at $21.32,16.44,16.23$ and -0.46 p.p.m. in addition to the isobutyl group part, suggesting the formation of the star structure (Supplementary Figure S3). The ${ }^{29} \mathrm{Si}-\mathrm{NMR}$ spectrum of 9POSIB showed two large peaks at -67.75 and -67.89 assigned to the isobutyl POSS moiety and two small peaks at 12.08 and -108.04 assigned to the linker parts (Supplementary Figure S7). The MALDI-

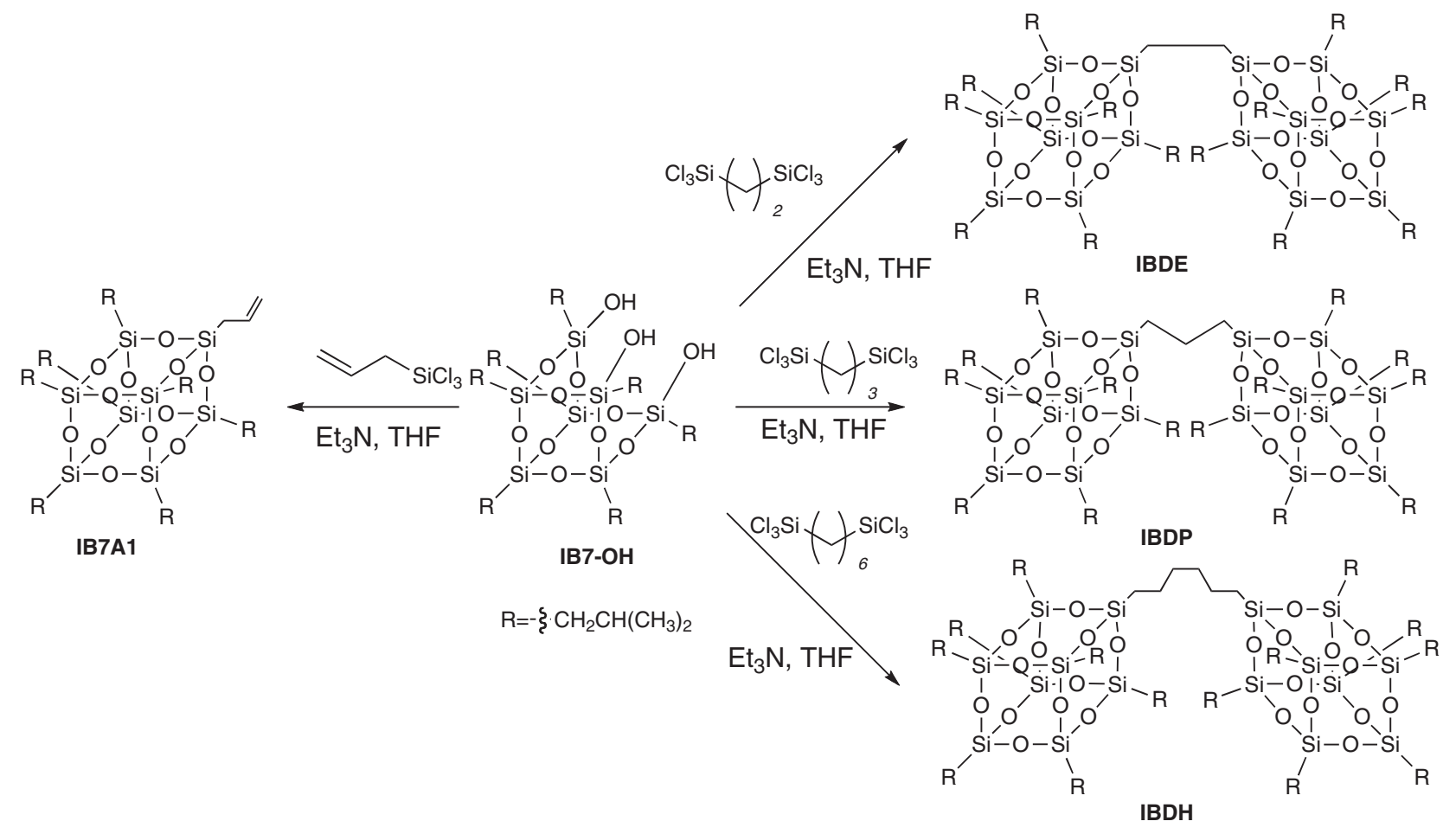

Scheme 1 Syntheses of various POSS derivatives. POSS, polyhedral oligomeric silsesquioxane. 

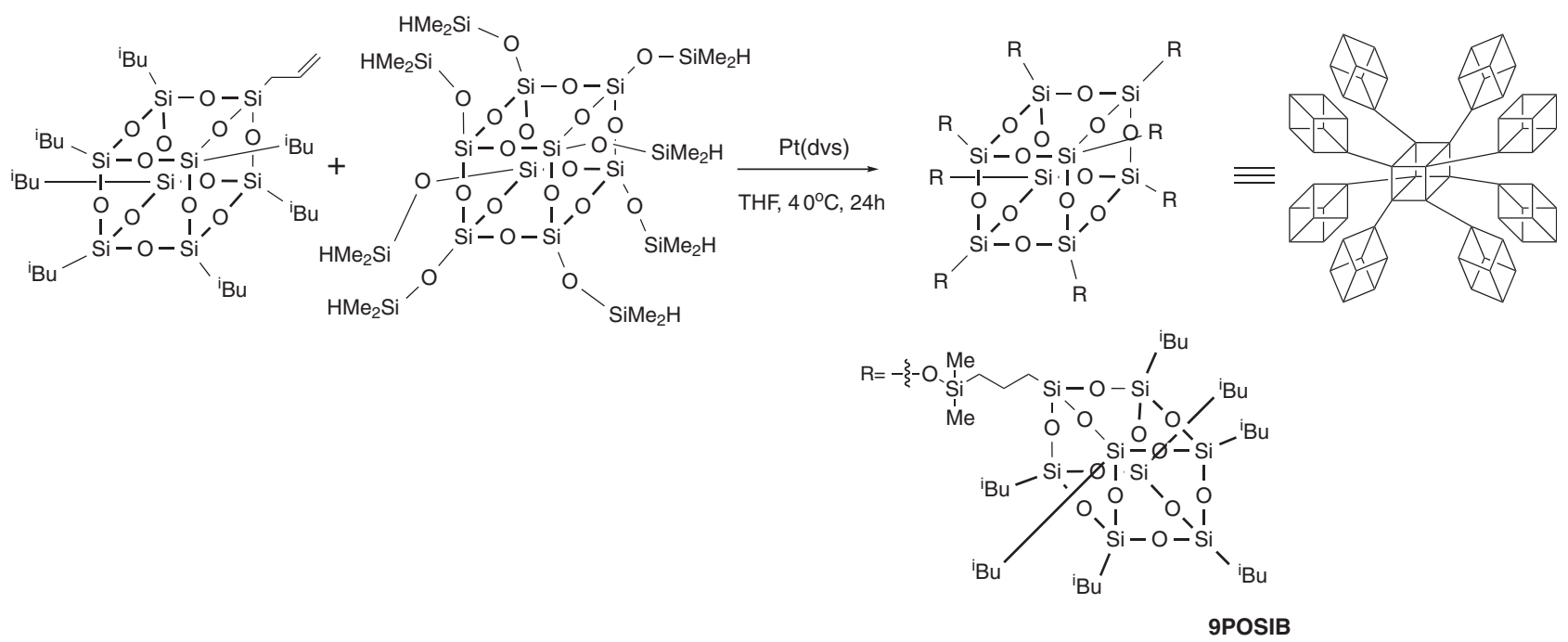

Scheme 2 Syntheses of the star-shaped POSS derivative. POSS, polyhedral oligomeric silsesquioxane.

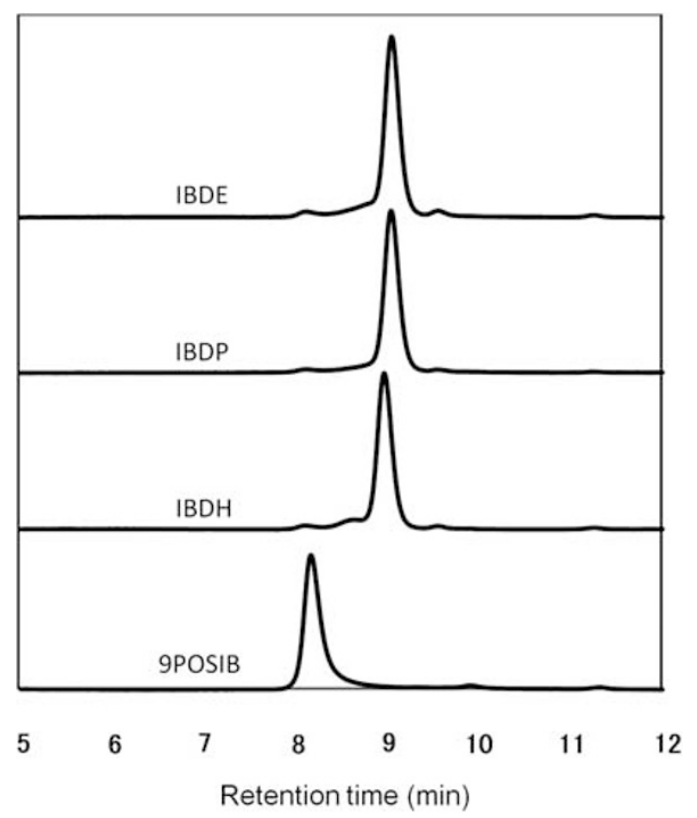

Figure 1 GPC traces of the purified POSS derivatives measured by TSK-gel super HM-H column using THF as an eluent with refractive index (RI) detection. GPC, gel-permeation chromatography; POSS, polyhedral oligomeric silsesquioxane.

TOF-MS results also agreed with the theoretical value and provided conclusive evidence for the formation of the star structure.

The solubilities of the dumbbell- and star-shaped POSS derivatives are summarized in Table 1 . All of the molecules were soluble in hydrocarbons such as hexane, octane and toluene and in chlorocarbons such as chloroform. Polar solvents, such as methanol and acetone, hardly dissolve the dumbbell- and star-shaped POSS derivatives. The solubility of 9POSIB was higher than that of the dumbbellshaped POSS derivatives.

Film-forming ability and optical characteristics

We studied the film-forming ability of IBDE, IBDP, IBDH and 9POSIB solutions on glasses by spin coating the solutions onto glass pieces and subsequently baking at $120^{\circ} \mathrm{C}$ for 3 min using a hot plate. The coating solutions were prepared by dissolving POSS derivatives in octane/hexane at $8 \mathrm{wt} \%$. We found that only the 9POSIB solution formed a transparent film. Opaque whitish films were formed for coating solutions using the dumbbell-shaped POSS derivatives. The 9POSIB film had a thickness of $1.3 \mu \mathrm{m}$, as measured by the prism coupler. The thicknesses of the other opaque films should be similar to that of the 9POSIB film because the coating conditions and solution concentrations were the same. Optical transmittance of the film obtained from the 9POSIB solution was $>99 \%$ in the visible region between 780 and $380 \mathrm{~nm}$ (Figure 5). In our previous study, ${ }^{10}$ trifluoropropyl-substituted dumbbell-shaped POSS derivatives demonstrated good transparent film-forming ability. However, alternation of the trifluoropropyl group to the isobutyl group reduced the film-forming ability. However, we found here that 9POSIB formed a transparent film.

To compare the optical characteristics of the 9POSIB film with those of a corresponding random silsesquioxane, a random silsesquioxane precursor (Ran-9POSIB-Pre) of the same composition as that of 9POSIB was prepared from isobutyltrimethoxysilane, propyltrimethoxysilane, dimethyldimethoxysilane and tetraethoxysilane using the sol-gel method. A 2-propanol solution of Ran-9POSIB-Pre was spin coated onto a soda-lime glass piece and baked at $200^{\circ} \mathrm{C}$ to form a transparent film, which was labeled as Ran-9POSIB. The refractive indices at $632.8 \mathrm{~nm}$ of the films from the 9POSIB and Ran-9POSIB solutions were 1.4567 and 1.444 , respectively. It was reported that an increase in cage structure ratio in a methyl silsesquioxane network structure decreases the refractive index. ${ }^{13}$ Here, the star-shaped POSS derivatives may form a more packed structure than the random silsesquioxane, leading to a higher refractive index for the 9POSIB film when compared with that for the Ran-9POSIB film.

Baking of the Ran-9POSIB-Pre solution at $120^{\circ} \mathrm{C}$ resulted in a viscous liquid for which the refractive index was not measurable by a prism coupler. Such low-temperature baking is insufficient for complete condensation, which increases the refractive index compared with those of sufficiently condensed silsesquioxanes. ${ }^{6}$ The random silsesquioxanes thus require curing at a high temperature. However, the 9POSIB solution demonstrated a film-forming ability under a lower-temperature process. The 9POSIB film is a new thermoplastic optical material derived from a single POSS compound as dumbbell-shaped trifluoropropyl-substituted C3-linked POSS and C6-linked POSS. 

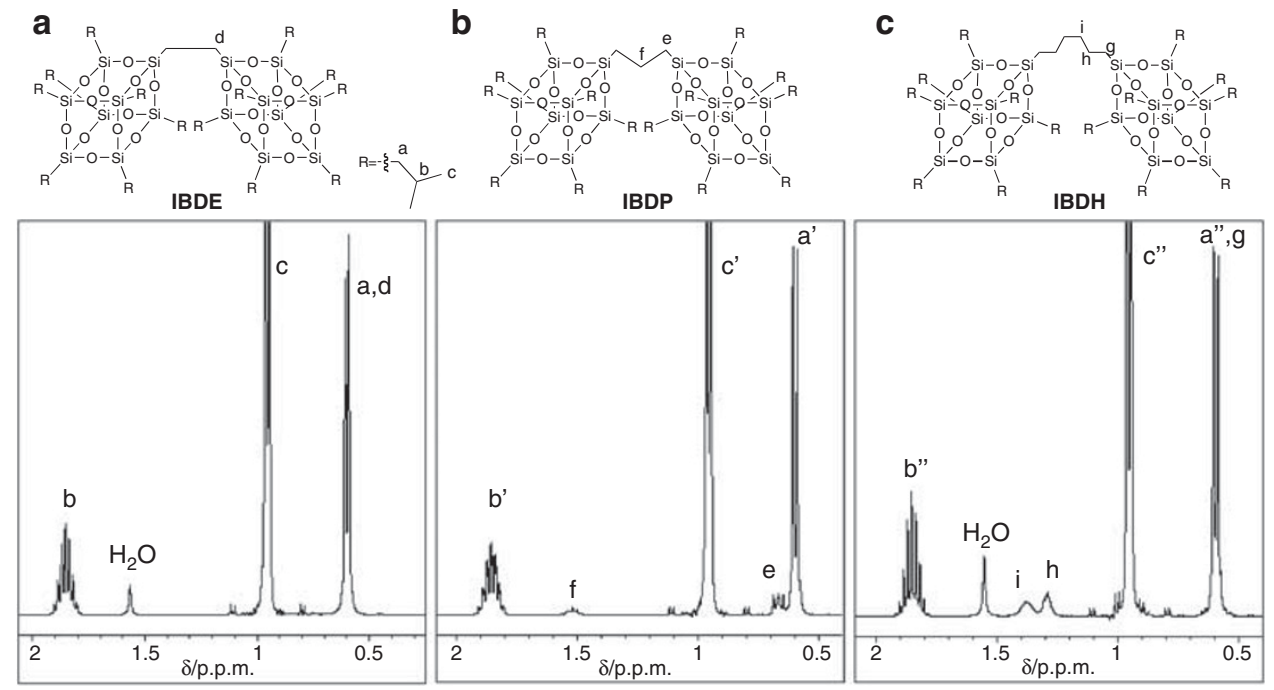

Figure $2{ }^{1} \mathrm{H}-\mathrm{NMR}$ spectra of (a) IBDE, (b) IBDP and (c) IBDH in $\mathrm{CDCl}_{3}$. IBDE, 1,2-bis(heptaisobutyl-T8-silsesquioxy)ethane; IBDH, 1,6-bis(heptaisobutylT8-silsesquioxy)hexane; IBDP, 1,3-bis(heptaisobutyl-T8-silsesquioxy)propane; NMR, nuclear magnetic resonance.

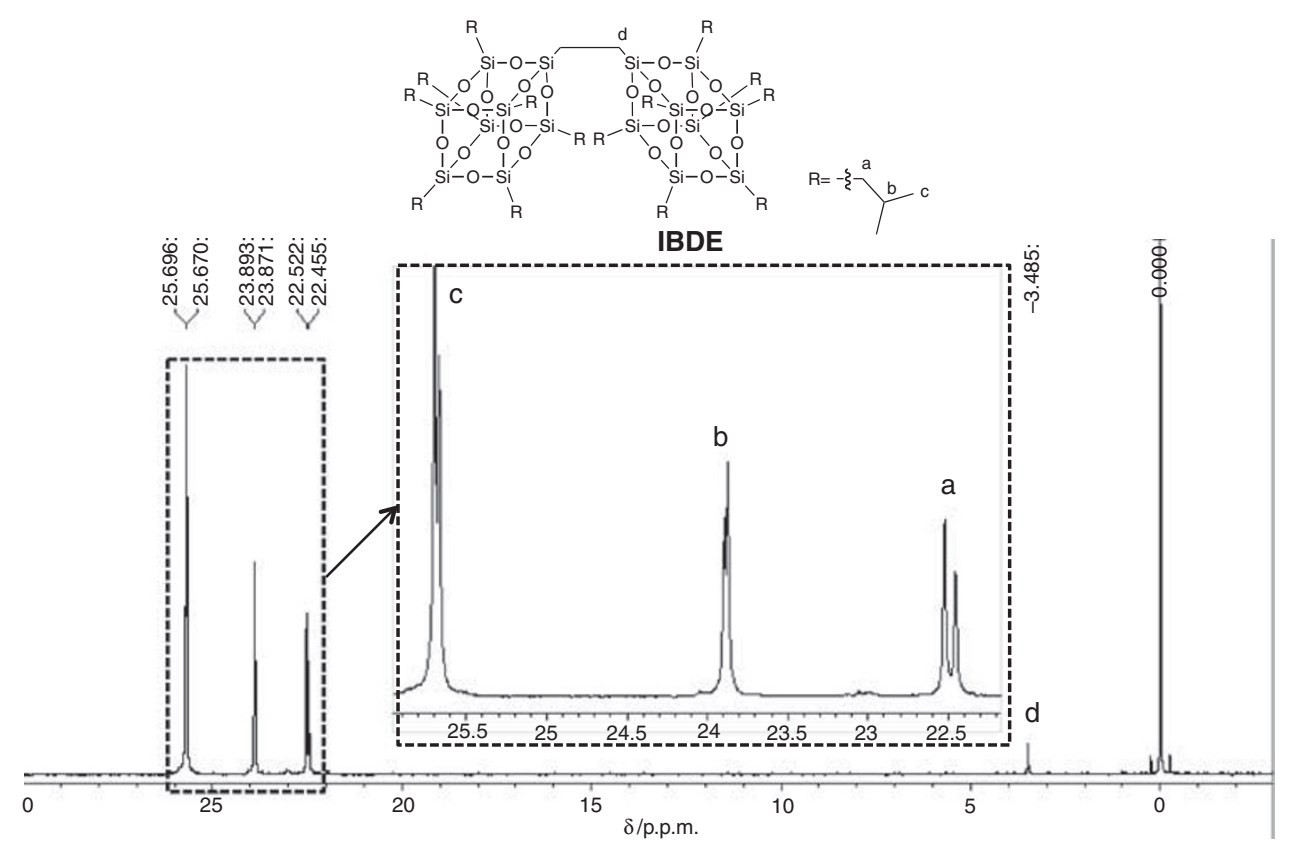

Figure $3{ }^{13} \mathrm{C}$-NMR spectrum of IBDE in $\mathrm{CDCl}_{3}$. IBDE, 1,2-bis(heptaisobutyl-T8-silsesquioxy)ethane; NMR, nuclear magnetic resonance.

\section{Thermal characteristics}

The thermal stabilities of the dumbbell- and star-shaped POSS derivatives were evaluated by thermogravimetric analysis. Thermogravimetric analysis traces of the POSS compounds considered in this study are shown in Figure 6. Although IB7A1 exhibited a $10 \mathrm{wt} \%$ loss at $229^{\circ} \mathrm{C}$ due to sublimation, the dumbbell-shaped POSS derivatives demonstrate higher thermal stability. IBDE, IBDP, IBDH and 9POSIB exhibited a $10 \mathrm{wt} \%$ loss at $306,293,317$ and $439^{\circ} \mathrm{C}$, respectively. Although IBDE and IBDH exhibited almost 100\% mass-loss due to sublimation, IBDP and 9POSIB are not sublime. The star-shaped POSS derivative showed significantly higher thermal stability than did the dumbbell-shaped POSS derivatives. In the case of 9POSIB, a mass increase was observed for temperatures $>600^{\circ} \mathrm{C}$. A possible reason for this observed mass increase is the formation of a nanoporous structure by the sintering of 9 POSIB under nitrogen and subsequent adsorption of gaseous molecules onto the pores.

Differential scanning calorimeter traces of the dumbbell- and starshaped POSS derivatives are shown in Figure 7. The star-shaped POSS derivatives exhibited a clear baseline shift at $24^{\circ} \mathrm{C}$, indicative of the glass-transition temperature. However, IBDE, IBDP and IBDH exhibited small endothermic peaks between -50 to $50{ }^{\circ} \mathrm{C}$ and no clear baseline shift. Water absorption under a cooling process before the measurement likely influenced these peaks. The melting points of IBDE, IBDP, IBDH and 9POSIB were observed at 231, 231, 239 and $96^{\circ} \mathrm{C}$, respectively (Figure 7a). These results indicate that the starshaped structure leads to a significantly lower melting point compared 


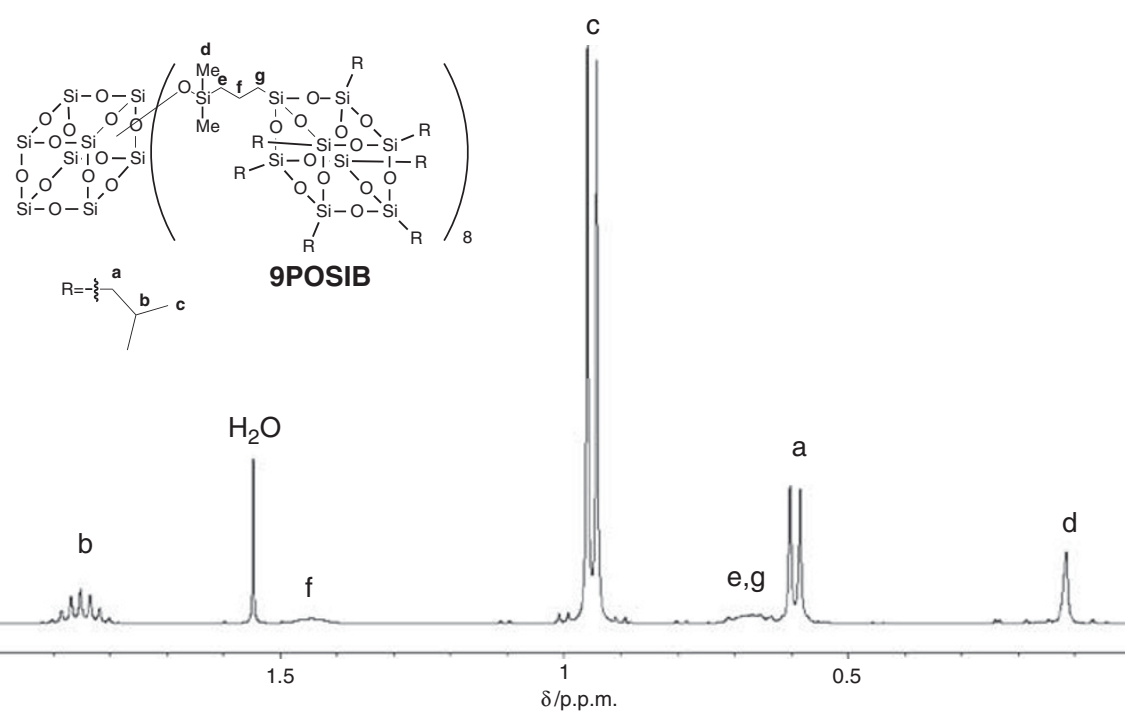

Figure $4{ }^{1} \mathrm{H}$-NMR spectrum of 9POSIB in $\mathrm{CDCl}_{3}$. 9POSIB, octakis[3-(heptaisobutyl-T8-silsesquioxy) propyldimethylsiloxy]-Q8-silsesquioxane; NMR, nuclear magnetic resonance.

Table 1 Solubilities of the dumbbell- and star-shaped POSS derivatives

n-Hexane Octane Toluene $\mathrm{CHCl}_{3}$ THF EtOAc Acetone DMF MeOH

\begin{tabular}{llllllllll}
\hline $\mathrm{IBDE}$ & + & + & + & + & + & \pm & - & - & - \\
$\mathrm{IBDP}$ & + & + & + & + & + & \pm & - & - & - \\
$\mathrm{IBDH}$ & + & + & + & + & + & \pm & - & - & - \\
$9 \mathrm{POSIB}$ & + & + & + & + & + & \pm & - & \pm & -
\end{tabular}

Abbreviations: DMF, N,N-dimethylformamide; IBDE, 1,2-bis(heptaisobutyl-T8-silsesquioxy) ethane; IBDH, 1,6-bis(heptaisobutyl-T8-silsesquioxy)hexane; IBDP, 1,3-bis(heptaisobutylT8-silsesquioxy)propane; 9POSIB, octakis[3-(heptaisobutyl-T8-silsesquioxy) propyldimethylsiloxy]Q8-silsesquioxane; THF, tetrahydrofuran.

+ , soluble; \pm , partly soluble; - , insoluble.

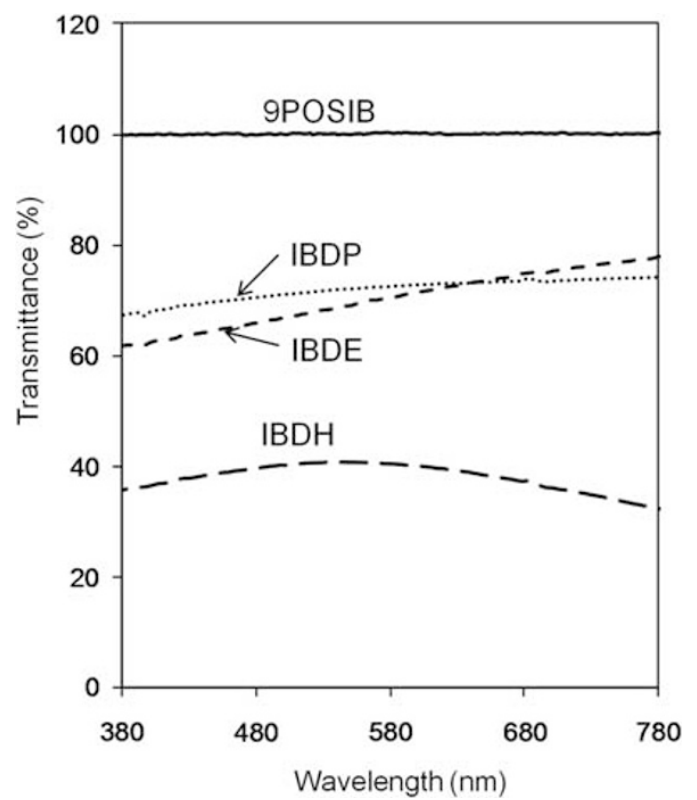

Figure 5 UV-spectra of the films obtained from solutions of IBDE, IBDP, IBDH, and 9POSIB on soda lime glass. IBDE, 1,2-bis(heptaisobutyl-T8silsesquioxy)ethane; IBDH, 1,6-bis(heptaisobutyl-T8-silsesquioxy)hexane; IBDP, 1,3-bis(heptaisobutyl-T8-silsesquioxy)propane; 9POSIB, octakis[3-(heptaisobutylT8-silsesquioxy) propyldimethylsiloxy]-Q8-silsesquioxane; UV, ultraviolet.

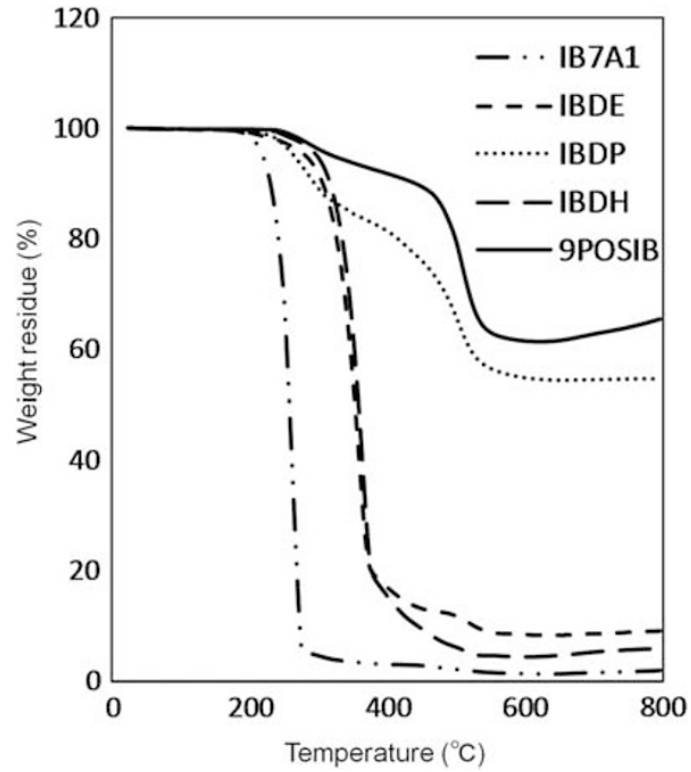

Figure 6 TGA thermograms of IB7A1, IBDE, IBDP, IBDH and 9POSIB at a ramp rate of $10^{\circ} \mathrm{C}$ per min in $\mathrm{N}_{2}$ flow. IBDE, 1,2-bis(heptaisobutyl-T8silsesquioxy)ethane; IBDH, 1,6-bis(heptaisobutyl-T8-silsesquioxy)hexane; IBDP, 1,3-bis(heptaisobutyl-T8-silsesquioxy)propane; 9POSIB, octakis[3(heptaisobutyl-T8-silsesquioxy) propyldimethylsiloxy]-Q8-silsesquioxane; TGA, thermogravimetric analysis.

with the dumbbell-shaped structures. The lower melting point and the appearance of the glass-transition point in 9POSIB suggest its lower crystallinity, which promotes the formation of a transparent film. Most of the reported POSS derivatives containing isobutyl groups exhibit melting points $>100{ }^{\circ} \mathrm{C}$. In our previous report, we stated that lower symmetries of the POSS derivatives decrease their crystallinity and lead to the ability to form optically transparent films. In this study, 9POSIB solutions formed good optically transparent films despite the single POSS molecule with high symmetry. This is due to the eight flexible linkers between the POSS units, which may inhibit the crystallinity of 9POSIB. 
a

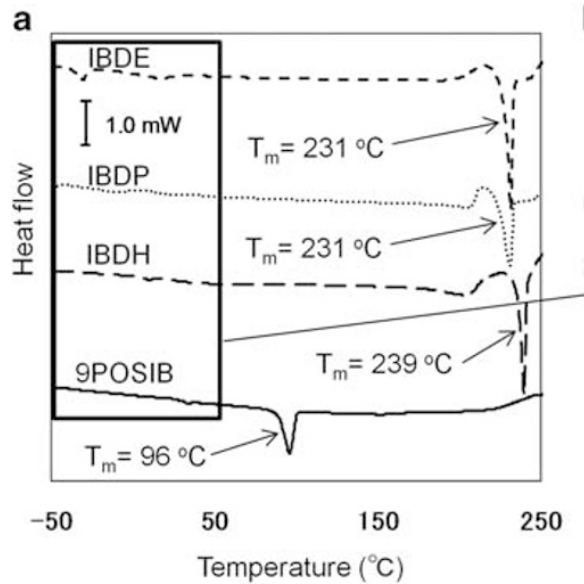

b

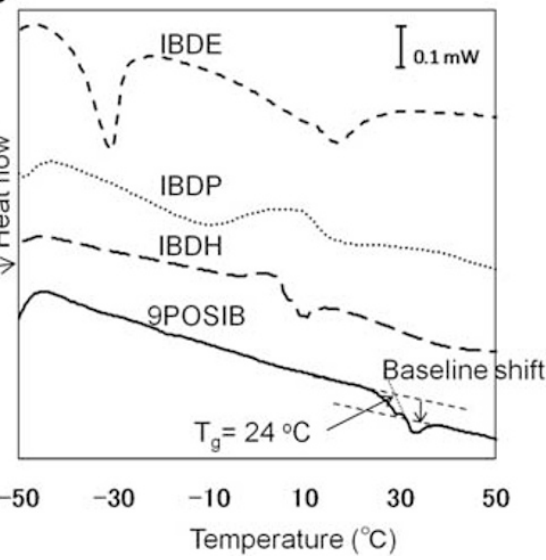

Figure 7 (a) DSC curves of IBDE, IBDP, IBDH and 9POSIB at a ramp rate of $10^{\circ} \mathrm{C}$ per min in $\mathrm{N}_{2}$ flow for the entire temperature range. (b) Expanded curves of 9POSIB around the glass-transition temperature. DSC, differential scanning calorimetry; IBDE, 1,2-bis(heptaisobutyl-T8-silsesquioxy)ethane; IBDH, 1,6-bis(heptaisobutyl-T8-silsesquioxy)hexane; IBDP, 1,3-bis(heptaisobutyl-T8-silsesquioxy)propane; 9POSIB, octakis[3-(heptaisobutyl-T8-silsesquioxy) propyldimethylsiloxy]-Q8-silsesquioxane.

\section{CONCLUSIONS}

We synthesized the star- and dumbbell-shaped isobutyl-substituted POSS derivatives linked by simple aliphatic chains and studied their optical and thermal characteristics. The star-shaped POSS derivative was produced by hydrosilylation of the octahydrosilyl POSS and the monoallyl POSS. The dumbbell-shaped POSS derivatives were produced by a corner-capping reaction between the incomplete cage compound and bistrichlorosilane compounds. The structures of all of POSS derivatives were confirmed by ${ }^{1} \mathrm{H}-,{ }^{13} \mathrm{C}-,{ }^{29} \mathrm{Si}-\mathrm{NMR}$ and MALDI-TOF-MS analyses. In our previous report, the trifluoropropyl-substituted dumbbell-shaped POSS compounds linked by the same aliphatic chains formed optical transparent films. However, the present dumbbell-shaped POSS compounds formed opaque whitish films. These observations suggest that alternation of the trifluoropropyl group to the isobutyl group reduces the film-forming ability. Our previous report also showed that the melting point of the transparent film-forming dumbbell-shaped trifluoropropyl-substituted C3-linked POSS and C6-linked POSS were observed at 211 and $194{ }^{\circ} \mathrm{C}$, respectively. ${ }^{10}$ All of the present dumbbellshaped isobutyl-substituted POSS derivatives exhibited higher melting points than did the transparent film-forming trifluoropropyl-substituted ones due to their higher crystallinity, which induced rough surfaces that inhibited the formation of transparent films. We found that spin coating and subsequent baking at $120^{\circ} \mathrm{C}$ resulted in the starshaped POSS compound forming optically transparent films. Although the melting points of the dumbbell-shaped POSS compounds were $\sim 230^{\circ} \mathrm{C}$, which is close to their decomposition temperature, that of the star-shaped POSS had a significantly lower melting point of $<100^{\circ} \mathrm{C}$, and its decomposition temperature was higher than $400^{\circ} \mathrm{C}$. 9POSIB solutions are regarded as sources of new thermoplastic optical materials derived from a single POSS compound and exhibited excellent filmforming ability with a low-temperature process.

\section{CONFLICT OF INTEREST}

The authors declare no conflict of interest.

1 Baney, R. H., Itoh, M., Sakakibara, S. \& Suzuki, T. Silsesquioxanes. Chem. Rev. 94, 1409-1430 (1995).

2 Lee, J. H., Kim, W. C., Min, S. K., Ree, H. W. \& Yoon, D. Y. Synthesis of poly(methyl-cotrifluoropropyl)-silsesquioxanes and their thin films for low dielectric application. Macromol. Mater. Eng. 288, 455-461 (2003).

3 Mikoshiba, S. \& Hayase, S. Preparation of low density poly(methylsilsesquioxane)s for LSI interlayer dielectrics with low dielectric constant. Fabrication of Angstrom size pores prepared by baking trifluoropropylsilyl copolymers. J. Mater. Chem. 9, 591-598 (1999).

4 David, B. C., Paul, D. L. \& Franck, R. Recent developments in the chemistry of cubic polyhedral oligosilsesquioxanes. Chem. Rev. 110, 2081-2173 (2010).

5 Laine, R. M. Nanobuilding blocks based on the $\left[\mathrm{OSiO}_{1.5}\right]_{x}(x=6,8,10)$ octasilsesquioxanes. J. Mater. Chem. 15, 3725-3744 (2005).

6 Lee, E. C. \& Kimura, Y. Structural regularity of poly(phenylsilsesquioxane) from the low molecular weight hydrolysates of trichloropheylsilane. Polym. J. 30, 234-242 (1998).

7 Unno, M., Suto, A. \& Matsumoto, H. Pentacyclic laddersiloxane. J. Am. Chem. Soc. 124, 1574-1575 (2002)

8 Choi, J., Yee, A. F. \& Laine, R. M. Toughening of cubic silsesquioxane epoxy nanocomposites using core-shell rubber particles: a three-component hybrid system. Macromolecules 37, 3267-3276 (2004).

9 Zhang, C., Babonneau, F., Bonhomme, C., Laine, R. M., Soles, C. L., Hristov, H. A. \& Yee, A. L. Highly porous polyhedral silsesquioxane polymers. synthesis and characterization. J. Am. Chem. Soc. 120, 8380-8391 (1998).

10 Araki, H. \& Naka, K. Syntheses of dumbbell-shaped trifluoropropyl-substituted poss derivatives linked by simple aliphatic chains and their optical transparent thermoplastic films. Macromolecules 44, 6039-6045 (2011).

11 Wada, K., Watanabe, N., Yamada, K., Kondo, T. \& Mitsudo, T. Synthesis of novel starburst and dendritic polyhedral oligosilsesquioxanes. Chem. Commun. 41, 95-97 (2005).

12 Wang, X., Ervithayasuporn, V., Zhang, Y. \& Kawakami, Y. Reversible self-assembly of dendrimer based on polyhedral oligomeric silsesquioxanes (POSS). Chem. Commun. 47, 1282-1284 (2011).

13 Lee, L. H., Chen, W. C. \& Liu, W. C. Structural control of oligomeric methyl silsesquioxane precursors and their thin-film properties. J. Polym. Sci. Part A: Polym. Chem. 40, 1560-1571 (2002).

Supplementary Information accompanies the paper on Polymer Journal website (http://www.nature.com/pj) 